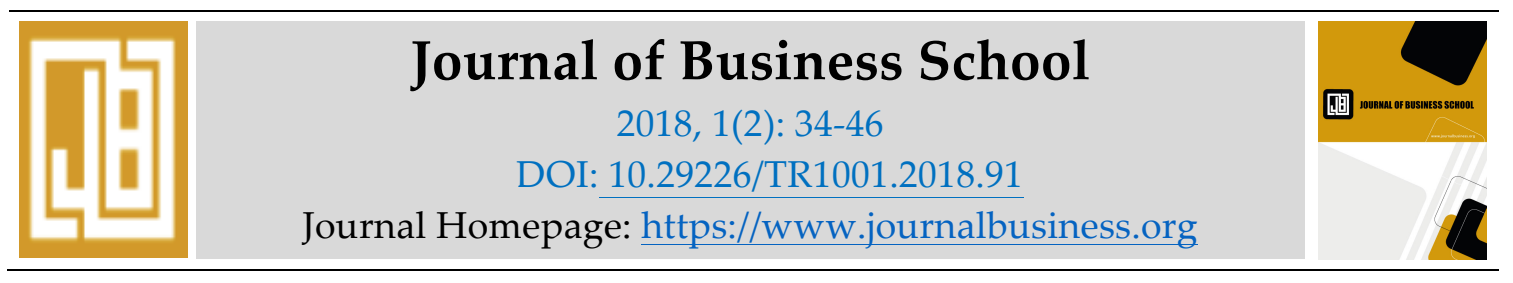

\title{
Bounded Rationality in Decision-Making
}

José G. Vargas-Hernández, M.B.A.; Ph.D.

University Center for Economic and Managerial Sciences. University of Guadalajara

Periférico Norte 799, Edif G201-7, Núcleo Universitario Los Belenes

Zapopan, Jalisco, 45100, México, Jvargas2006@gmail.com

\section{Ricardo Pérez Ortega}

Maestría en Negocios y Estudios Económicos.

Centro Universitario de Ciencias Económico Administrativas. Universidad de Guadalajara,

Periférico Norte 799, Edif G201-7, Núcleo Universitario Los Belenes

Zapopan, Jalisco, 45100, México

\begin{abstract}
The purpose of this paper is to study the relationship between rationality and decision making. As a specific objective it will be explained the benefit of learning in the decision making process derived from its results. The research question is: How does bounded rationality impact the decision making of organizations? The initial hypothesis is that the organization, as a social system, seeks to maintain the balance between the behavior that determines the positions of people and the structure of values and beliefs shared among them, but that is bounded to the rationality of the decision maker. The research method used is descriptive, being a qualitative analysis, that follows from the understanding of the behavioral theory of the firm also the behavioral decision theory, in terms of behavioral decision-making processes and the analysis through learning. The main conclusion is that bounded rationality occurs when companies lack context information of the results of their actions, being forced to make less than optimal decisions because they have to adjust to the conditions in which they operate. Decisions involve a commitment of large amounts of resources of the organization for the fulfillment of the objectives and purposes of the organization through the appropriate means. These means can be translated into models that help reduce the limits of rationality in organizations.
\end{abstract}

Keywords: Decision making, bounded rationality, learning process.

\section{Introduction}

This document is a reflection of the decision-making process in organizations, and the growth of companies through the behavioral theory of the firm. Decision making is analyzed from the point of view of bounded rationality, this with the aim of clarifying how decisions are made considering the human aspect of who decides. From a general point of view, the decision is an act that leads to the action of choosing between different alternatives. The adequate selection of 
these depends, to a large extent, on their success or failure, since they must cover the risk, certainty and uncertainty inherent in the decision and the action (Egan, 2007).

In organizations there is evidently a complex network of decisions and actions, the latter consisting of events that can be attributed to a system (Luhmann, 1997), while the decision finds its identity in the choice between alternatives, understanding that the decisions are much more sensitive to context than actions and, therefore, not equal to stable. Simon (1947) describes how organizations influence the decisions of their members, trying to make them compatible with the global objectives of the organization.

The theory of decision making, under different schemes, indicates the steps for a decision to be rational (Eduards, The theory of decision making, 1954). The people in charge try to do it this way, but in the real world it is not always possible. It is argued that an adequate study of human behavior in organizations should take into account the motivational, attitude and rational aspects of human behavior. In this way, both the works of economists on planning processes and the work of psychologists on organizational communication and problem solving capacities (March and Simon 1958), cited in (Vargas-Hernández, Guerra-García, BojórquezGutiérrez, \& Bojórquez-Gutiérrez, 2014).

In this regard, Cyert \& March (1963) in their book "A Behavioral Theory of the Firm" offered four main research topics; a) A small number of key economic decisions, b) Development of a general theory, generalizing the results of studies of specific companies, c) Linking empirical data to models, d) Orientation towards the process instead of the results. They argue that, the behavior approach takes the company as the basic unit of analysis, trying to predict the behavior with respect to the decisions of price allocation, production and resources; the decision-making process is emphasized.

On the other hand, economists and some psychologists have produced a large number of theories and experiments that have to do with decision-making with a particular focus on rational behavior.

Alfred Marshall proclaimed in his principles of economics that economics was a science of psychology, stating:

Economy is a study of humanity in the ordinary business of life; examines that part of individual and social action that is most closely related to achievement and to the use of material welfare requirements. Therefore, it is on the one hand a study of wealth; and on the other hand, and more importantly, a part of the study of man. Because the character of man has been shaped by his daily work and the material resources that he therefore seeks, rather than by any other influence, unless it is that of his religious ideals. Marshall, 1890, (quoted by Simon, 1979, p.493)

Subscribing to the previous contribution, Simon (1979) mentions that economic science has focused on a single aspect of human character, which is the use of reason, and particularly the application of it to problems of decision making. The organization, as a social system, seeks to maintain the balance between the behavior that determines the positions of people and the structure of values and beliefs shared among them, that import a certain order between individuals and the dynamics of organizations.

The behavioral theory of the firm takes from the theory of games, and research of operations, between several branches of social sciences in which there is interdependence and 
complementarity; models to express a way of anticipating problems, and simulate a solution of them in a given context. This document will not address these models in detail.

Why bounded rationality? Answering this question is not possible only in one way, that is why Conslick (1996) provides four reasons; the first, there is abundant empirical evidence that is important. Second, models of bounded rationality prove themselves. Third, justifications that assume that rationality is not bounded are not convincing in general. Fourth, the deliberation of an economic decision is a costly activity and a good economic decision requires that all costs be covered.

\section{Background of the study of bounded rationality in decision making}

In recent years there has been growing interest in the description of decision making that refers and analyzes the way people perform these actions in real contexts, which mostly prevents them from taking them rationally and in what conditions they will actually be relatively rational. This problem was analyzed by Barnard (1938), in which he defined formal organization as a consciously coordinated system of activities or forces of two or more people; He also emphasized the role of the informal organization, in which the individual personality is maintained against certain effects of the formal organization that tends to disintegrate the personality. In fact, Barnard (1938) concludes that: "the expansion of cooperation and development of the individual are mutually dependent realities, and that due to a proportion or balance between them is a necessary condition for human welfare" (p. 16).

This of course is related to the incentives of formal organizations, which are related to the social capacity in which people feel in the work environment, the condition of communion or camaraderie. On the other hand, authority is also mentioned as the character of a communication or order in a formal organization by virtue of which the dependents accept that order. The latter has greater impact on the issue of decision making, since the holder of the authority must have the rationality to take an action from among the alternatives within his reach and communicate this to his dependents through the authority that he enjoys.

From this point one of the fundamental problems of the organizations with respect to the communication begins, since the signature is considered like a processor of information more efficient than the individual, having failures in the communication or understanding, deriving from her a complex system cognitive called bounded rationality, of which the behavioral theory of the firm centers its study (Simon H., 1955).

After Barnard, one of the authors of the Behavioral theory of the firm, Herbert Simon, describes the importance of organizations in the decision-making of its members, considering these organizations remove such individuals as part of their autonomy and replace it with an organizational process of decision making (Vargas-Hernández et al., 2014). In this theory is provided a self-conscious attempt to develop linguistic and conceptual tools appropriate to reality, and meaningfully applied to organizations. The main thesis of Simon (1947) is that decision making forms the heart of the organization, and that the vocabulary of organizational theory must be derived from the logic and psychology of human choice.

From the perspective of the vision of rational systems, the behavior of organizations is considered as actions carried out by determined and coordinated agents. In this sense, Simon (1947) is consistent with the logic of economics and uses the flow of information, efficiency, implementation and design. Insists on reaching good terms with cognitive limitations, implying that the rationality of the behavior of organizations with clearly specific limitations. Regarding bounded rationality, Simon (1947) observes that a person does not live for years in a particular position in an organization, exposed to some currents of communication, protected from others, 
without profound effects on what the person knows, believes, wait, emphasize, fear and propose.

So, the organization provides positions of responsibility to exercise authority and influence over others, executives who make decisions and take actions, they must do so with an eye on the situation and another eye on the effects of this decision and future effects on the organization. This means that decisions are also influenced by the authority relationship. The major contribution of Simon (1947) to the economics of the organization is the argument that it is precisely in the realm where human behavior is intentionally rational, but only in a bounded way.

Organizational behavior is the theory of intentional and bounded rationality: it is about the behavior of humans that satisfy because they do not have the capacity to maximize (Simon, 1947). While the "economic man" maximizes and selects the best alternative among all available, the "man of the organization" satisfies, seeks a course of action that is satisfactory or "good enough." The economic man deals with the real world "in all its complexity. The world organization that man perceives is a drastically simplified model of the real world (Eduards, The theory of decision making, 1954).

The limits of rationality are the central theme that is addressed in this document. Rationality requires a choice between all possible alternative behaviors, in reality only a few of those alternatives come to mind. Complete rationality is "bounded" by the lack of knowledge. At the simplest level, performance may be bounded by manual dexterity or reaction time, and decision-making processes may be bounded by the speed of mental processes (Simon., 1979). Individuals are also bounded by their values and the conceptions of purpose that influence them in making their decisions, and these tend to be shaped by their organizational experience.

For example, if the loyalty of the executives of the organization is high, their decisions can show sincere acceptance of the set of objectives given within the firm. As mentioned above, people are bounded by their knowledge of the relevant factors for their work. This limitation applies both to the basic knowledge required in decision-making (bridge designers must know the fundamentals of mechanics) and to the information required to make appropriate decisions in a given situation.

On the other hand, Cyert \& March, (1963) proposed that companies in reality, aim to "satisfy", instead of maximizing their results. That is, some groups can settle for "good enough" achievements instead of fighting for the best possible outcome. Again, this comes from bounded rationality. In the authors' model, the objectives are not established to maximize the relevant magnitudes, such as profits, sales and market share. Instead, the objectives are commitments negotiated by the groups of the organization. In the decision-making process the information is required to take the most appropriate, however, the collection of information by itself has a cost and requires resources.

The information is not transmitted immediately or automatically from its point of origin to the rest of the organization. Vargas-Hernández et al., (2014) affirm that there is often a lack of information transmission upwards, simply because subordinates cannot visualize the information with precision that their superiors need. These authors suggest that the problem also exists in an inverse situation, since the superior can retain information from subordinates; It can be accidental or fraudulent. This is a weight variable that affects rationality, again limiting the feasibility with which decisions are made. 
This current work focus on investigating the close relationship of the decision-making process and the rationality in them. Then the following research question will be pursued: What is the impact of bounded rationality in the decision making of organizations? In the study, only the relationship between the decision factor is analyzed, which in this case will depend on the bounded rationality of the person who performs the decision actions and what to do with the behavioral theory of the firm.

\section{Conceptual theoretical review}

\section{A. Bounded rationality}

It is known that behavior can be rational or irrational, then, it could be inferred that preferences, beliefs, expectations and the decision-making process are also. Cyert and March (1963) mention that the company is an institutional, functionally rational response to uncertainty and bounded rationality. How much of this can be observed in reality is to be doubted. Rationality in the real world is a complex concept, due to which there are numerous research works that argue that rationality is bounded by the lack of knowledge.

Human beings struggle for rationality, but it is restricted within the limits of their knowledge. The rational choice is feasible as the bounded set of factors on which the decision is based corresponds to a closed system of variables, Vargas-Hernández et al. (2014). This indicates that decisions can be made without taking into account the possible results derived from knowledge biases. A branch of the social sciences that tries to mitigate these biases, along with the economy, is operations research, however, the behavioral part is incorporated into these areas to try to explain and solve the limitations of the decision making in the firms.

A decision can be called objectively rational, if, in fact, it is the correct behavior to maximize the values given in a specific situation. A decision is subjectively rational if it maximizes achievement relative to the subject's actual knowledge (Mahoney Joseph, 2012). From this it can be inferred that an action is consciously rational insofar as the adjustment of the means to the ends is a conscious process. This resembles what economic man (homo economicus) represents, since it has characteristics such as being fully informed, sensitive and rational.

An economic man according to the theory of the decision, has complete information, assuming that he knows not only all the courses of action, but also his results. It is sensitive to the available alternatives. The crucial fact about the economic man is that he is rational. This means that their preferences are complete, transitive and that there are perfect substitutes; and on the other hand he makes his decisions to maximize his utility (Eduards 1954). The same author refers to the behavior in the decisions, mentioning that humans are neither perfectly consistent nor perfectly sensitive.

The above makes sense to the extent that it is understood that in the tensions that exist between society and the individual, there is a great demand to compete within the individual conscience. Where rational economic approach is to think individually, as well as the economic man who seeks to maximize its utility derived from instrumental rationality (rational choice). And since the capacity of the human mind to formulate and solve complex problems is very small compared to the size of the problems, whose solution is necessary for objectively rational behavior in the real world, instrumental rationality becomes, so to speak, bounded rationality.

The Theory of the instrumental rationality or rational choice, assumes that, in a situation of decision, the means, the information, the beliefs and personal analyzes, are optimal; the estimates of probabilities are easily realizable; the individual has at his disposal information about all possible alternatives and has a complete and consistent system of preferences that allows him to make a perfect analysis of all of them. It does not present difficulties or limits in 
the mathematical calculations that it must carry out to determine which is the best, therefore, it guarantees that the chosen alternative is a global optimum (Aumann, 1997).

The theory of bounded rationality, sees the decision process from a very different point of view. In the decision-making process, even in relatively simple problems, a maximum cannot be obtained since it is impossible to verify all possible alternatives. People differ in both available opportunities and desires (influenced by environmental factors). When an individual must decide, they influence him, both the desires that he possesses and the opportunities that he thinks he has. It is not certain that these beliefs are correct: it is possible that the individual is not aware of some opportunities that are actually viable to him or, he may believe that certain opportunities are favorable to him, which in reality are not, therefore it cannot be guaranteed that choose the best alternative (Elster, 1990).

As mentioned in Vargas-Hernández et al. (2014), about bounded rationality, referring to the fact that human behavior is rational first intention, but bounded by information asymmetry. And as mentioned earlier, the ability of the human mind to formulate and solve problems is small and is bounded by neuropsychological issues on the one hand and language limits on the other. Physical limits are the individual abilities to receive, retrieve and process information; those of language refer to the inability of individuals to articulate their knowledge or feeling by the use of a word, so that they can be understood by others (Williamson, 1979).

Table 1. Comparative Rational Choice and Bounded Rationality

\begin{tabular}{|l|l|}
\hline Bounded rationality & Rational choice \\
\hline $\begin{array}{l}\text { Necessity of assistance of the bounded mental } \\
\text { capacity of the subject that decides. }\end{array}$ & $\begin{array}{l}\text { Unbounded cognitive ability of the subject } \\
\text { who decides. }\end{array}$ \\
\hline Knowledge of an acceptable set of actions & Knowledge of all available actions. \\
\hline $\begin{array}{l}\text { Approximate and heterogeneous knowledge } \\
\text { of the consequences. }\end{array}$ & $\begin{array}{l}\text { Numerical knowledge of all the consequences } \\
\text { of actions. }\end{array}$ \\
\hline Evolutionary and unsettled preferences. & Stable and ordered preferences. \\
\hline $\begin{array}{l}\text { Temporary and cost limitation that affects the } \\
\text { quality of the decision. }\end{array}$ & $\begin{array}{l}\text { Unbounded or non-influential resources in the } \\
\text { decision-making process. }\end{array}$ \\
\hline Search for a satisfactory result & Search for the best possible result \\
\hline $\begin{array}{l}\text { Help the one who decides to understand what } \\
\text { will happen if he does something. }\end{array}$ & Inform the one who decides about what to do. \\
\hline
\end{tabular}

Source: Own elaboration with data from Simon (1957) and (2000).

\section{B. Decision Making}

The theory of the decision under the behavior Paul \& Fischhoff (1977), mentions that the decisions taken under a system of perceptions have, in a certain degree, to do with the uncertainty about the states of the environment in which the decision maker is. For example, who takes an umbrella depends on something that is not known with certainty that is the weather; or if you are a smoker, the decision will depend on the point of view of the loss of health due to smoking.

With this respect the theory of the decision making of Eduards (1954), three main ideas are assumed, first of all, there are options to choose from, so if a doctor wants to measure the reflexes when hitting the knee with a Neurological hammer, produces an automatic reaction, therefore there is no decision made (by the patient). However, from the doctor's point of view when he chooses between the two knees of the patient to hit, he makes a decision, because he has options (the legs). So, the theory of decision is about deciding with different options. 
Second, this theory assumes that decisions are made in a non-random way. So it does not make sense to investigate the mechanisms of decision making, if these decisions are random. And finally, as a third point it is assumed that the decisions are oriented in specific goals. In general, decision theory is concerned with goal-directed behavior, in the presence of options.

Paul \& Fischhoff (1977) mention that there are two types of decision theories; normative and descriptive. The first, explains how decisions should be made, the second describes how decisions are actually made. The behavioral decision theory in a descriptive way tries to explain the real behavior. In this context it makes sense to separate the decisions in different stages, then, different philosophers and psychologists, and scientists, separated the decision-making process in different stages, but more or less, all of them suggest, that first, we identify the problem, then, we collect information related to the problem; solutions are produced, alternatives are evaluated and finally selected among them. Figure 1 explains the above.

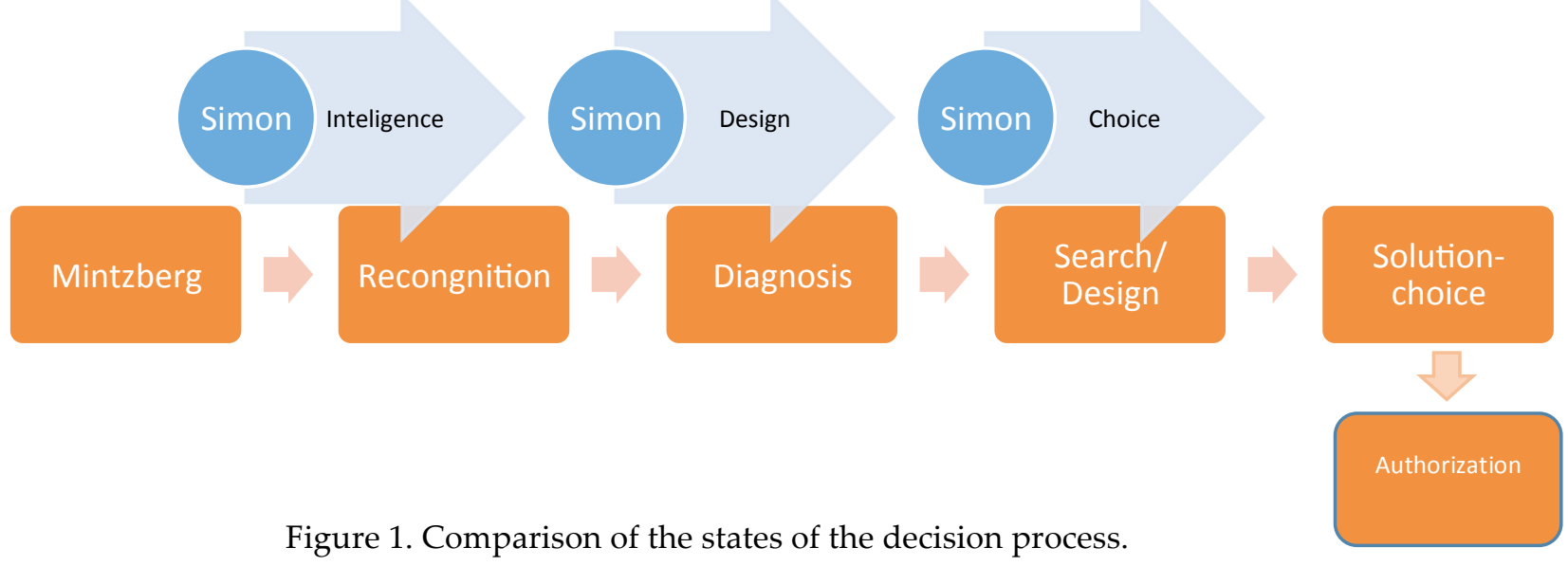

Source: Own elaboration with data from Simon (1982) and Mintzberg et. to the. (2001).

\section{Behavioral theory of the firm}

The behavioral theory of the firm has had an enormous influence on the theory of organization, strategic management, and socio-scientific research fields. Its central concepts have given motivation and foundation of theoretical and empirical works focused on the organizational phenomenon. In the present investigation the behavioral theory of the firm is used to explain the relationship in decision making and bounded rationality. The authors are mentioned, Barnad (1938) studied the functions of executives; where he emphasized the role of the individual personality in the informal organization, which subsists against the current of the formal organization. In the studies of administrative behavior, Simon (1947) and organizations March \& Simon (1958), a behavioral theory of the firm Cyert \& March (1963), were three contributions of the Carneige School that founded the scientific studies of the administration and behavior of the signature. Again Simon (1982) publishes a paper entitled "Models of Bounded Rationality". In the following paragraphs their contributions that form the behavioral theory of the firm will be analyzed.

\section{1) The functions of the executive of Barnard (1938).}

Barnard (1938) notes that successful cooperation is an abnormal condition rather than normal. In his work it is mentioned that, within innumerable failures of cooperation, it can see successes that survive these. Both the failures of cooperation and those of the organization are characteristic of human history. Its purpose is to provide a comprehensive theory of cooperative behavior in formal organizations. The main characteristics of the contribution of Barnard are: 
The willingness to cooperate, the ability to communicate and the existence and acceptance of a purpose. In this work it is argued that there is a zone of indifference in each individual, in which the orders are accepted without consciously questioning them about their authority.

It is pointed out that the art of executive decision making consists in not deciding questions that are not pertinent, in not deciding prematurely, in not making a decision that cannot be made effective, and in not making decisions that others must make. Such good judgment of the executive preserves morality, develops competence and preserves authority.

It is concluded that the expansion of cooperation and development of the individual are mutually dependent realities, and a due proportion or balance between them is a necessary condition for human well-being, Barnad (1938) cited in Mahoney (2012).

\section{2) Administrative behavior of Simon (1947).}

Simon's main thesis is that decision-making is the heart of the organization and must be derived from the logic and psychology of social choice. Three roles of the organization are highlighted: Organizations influence people's habits, organizations provide means to exert authority and influence over others; and organizations influence the flow of communications. Simon (1947) argues that it is precisely in the realm where the behavior is intentionally rational, but only in a bounded way, that there is room for a true theory of organization.

Organizational behavior is the theory of intentional and bounded rationality. In this sense, the term bounded rationality is used to designate a rational choice that takes into account the cognitive limitations of the person responsible for decision making, limitations of both knowledge and computational capacity. Bounded rationality is a central issue in the behavioral approach to economics, which is deeply rooted in the ways in which the actual decision-making process influences the actions that are taken.

Considering the brain as a scarce resource, Simon (1947) states that the information processing systems of modern civilization swim in an extremely rich soup of information. In a world of this kind, the scarce resource is not information; it is the processing capacity to attend to the information. Attention is the main bottleneck in the organization's activity, and the bottleneck becomes increasingly narrow as we move towards the top of the organizations.

\section{3) Organizations de March \& Simon (1958)}

This model imposes a responsibility on the managers, which is to continuously seek to complement the information of their assignment of tasks. An organizational model that neglects economic incentives will be, for most humans, a poor predictive model; and the behavior of the organization can often be predicted by knowing previous behaviors and routines (March \& Simon, 1958).

The characteristics of its organizational structure model was the optimization was replaced by the "satisfy", the alternatives of the action and its consequences are discovered sequentially through the search process, and each specific action deals with a bounded range of situations and a bounded range of consequences. It can be interpreted as the search is partially random, but in the effective search for problems is not blind, given that the design of a search process by itself is often an object of a rational decision (Mahoney Joseph, 2012)

\section{4) A behavioral theory of the firm of Cyert and March (1963)}

His work contains four research commitments: 1) Focus on a small number of key economic decisions made by the company; 2) Develop models oriented to company processes; 3 ) Link the 
company's models as close as possible to the empirical observations; and 4) Develop the theory with generality beyond the specific studies of the companies.

According to Cyert \& March (1963) the organizations consist of a series of coalitions and that the function of the administration is to achieve a quasi-resolution of conflicts and avoid uncertainty. The problematic search that is stimulated by a problem with (or lack of) an existing routine is assumed to be motivated, simplified and biased, reflecting unresolved conflicts within the organization.

\section{5) Models of bounded rationality by Simon (1982)}

To cover the conflict of objectives and uncertainty, Simon (1982) mentions that we need to know something about perceptual and cognitive processes to predict short-term behavior. Also, the filtering of information is not a passive process, but an active process of attention, which is influenced by hopes and desires. (Simon., 1979).

The abundance of information means the scarcity of something else: the scarcity of information consumed, the information consumes the attention of its recipients. Information systems need to listen and think more than they speak. Establishing the problem of organization in this way leads to a very different system design that deals with information overload, (Simon H. A., 1997).

In this work we also talk about two concepts, one called Substantive Rationality, which deals with an appropriate behavior for the achievement of the given goals within the limits imposed by the given restrictions. In this vision of the economy, given the objectives, the rational behavior is determined in its entirety by the characteristics of the environment in which said behavior develops. And the other concept is Procedural Rationality, which is a search for better heuristics (heart of intelligence). Organizational economics is a description and explanation of human institutions. Decision processes, like all other aspects of economic institutions, exist within human reasoning. This is subject to changes in what humans know, and with each change in their means of calculation, (Simon H. A., 1997). A commercial company equipped with the operations research tools does not make the same decisions, for example, in regards to inventory management, as it did before it possessed such tools (Simon., 1979).

In this work it is concluded that complexity is profound in the nature of things, and the discovery of approachable procedures and tolerable heuristics that allow to select large spaces selectively is the core of intelligence, whether human or artificial (Mahoney Joseph, 2012).

\section{Research methods}

The present investigation is of descriptive character, being a qualitative analysis that follows from the understanding of the behavioral theory of the firm of Simon (1947, 2000; Cyert and March, 1963), the theory of the behavior of the decisions, (Paul \& Fischhoff 1977; Busemeyer \& Bruza, 2012; Gonzalez \& Pegah, 2017), in terms of behavioral decision-making processes and their analysis through learning, which significantly influence the process of making decisions that help mitigate rationality bounded to a certain degree due to this key factor, which is learning. 


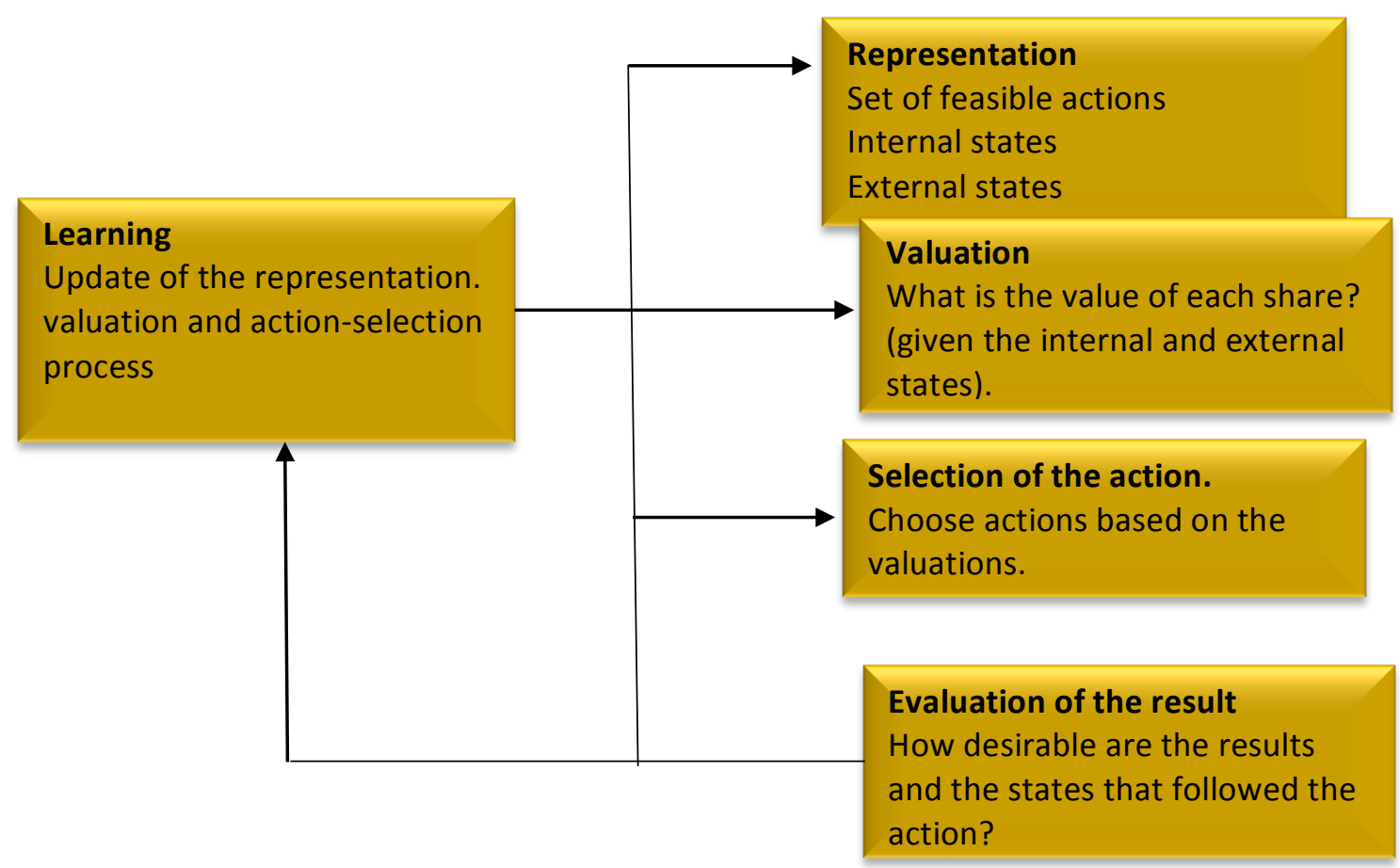

Figure 2. Behavioral process of decisions.

Sources: Own elaboration with information from Natural Reviews, Neurocience. Volume 9. July 2008.

As can be seen in figure 2, the main difference with respect to figure 1, is shown in the learning that adds value to the decision process is learning. From this valuable concept, the results of each action will be evaluated. The learning process can modify all the states of decision making. It is likely that flexibility, which characterizes learning by greater openness of ideas, greater discussions, allowing for the possibility of being creative contributing to rational decisions (Hart \& Banbury 1994), and in this way, mitigating its limitations, less in an aspect that is the adequate use of information, obtained through learning.

It is considered by what he mentions (Raport, 1975) that learning is of great importance because decisions are not always static. Static decisions are characterized by a single option and are often conceptualized as linear processes: one observes explicit alternatives and makes a decision, but one cannot learn from the consequences of those decisions (Gonzalez, 2012). Alternatives in typical static decisions are often described by probabilities and probabilities. A choice between an alternative that gives \$ 3 with security and one that gives \$ 4 with a probability of 0.8 and $\$ 0$ otherwise is an example of a static decision (Gonzalez \& Pegah, 2017).

There are other types of decisions that are dynamic decisions. These, in contrast to static ones, involve a sequence of choices made in an environment that can change exogenously or based on previous choices and where decisions are sequentially linked to each other through their effects so that an action at a specific time influences directly or indirectly future actions. Consider the previous example about finding the best couple. If we continue to see a person affects or not our chances of knowing a better or worse candidate. This can occur because dynamic environments vary in their inclusion of delayed feedback, interrelated actions and their effects over time, and dependence on time, where the value of actions is determined when an action is taken (Gonzalez \& Pegah, 2017). 
Simple tasks can have a dynamic complexity, arising from the relationship between the choices and their effects over time, from the sequential nature of these interdependencies, and the different lags between the actions and their effect on the environment and looking for the best partner is influenced by who we know and with whom we spend time, before making a marriage decision (Gonzalez \& Pegah, 2017).

According to figure 2 and the theoretical analysis of Raport (1975) another very common approach for the modeling of learning in the tasks of the decision-making process is reinforcement learning (Reinforcemente Learning from now on RL). In a typical RL problem, an agent tries to find an association between an observed result and the previous actions using either its memory or environmental cues. An agent performs an action in each state (for example, by selecting an option in a binary choice task) and the environment delivers a reward or punishment based on the action state pair and changes the agent's current state. It is important to note that an RL agent tries to estimate the dynamics of the environment when experiencing it.

\section{Analysis of results}

As discussed above, an agent learns how good or bad each action is, based on the reward received. These characteristics can be probabilistic or deterministic and can be modified dynamically over time (Busemeyer \& Bruza, 2012). This vision of the learning process originates in the work of Simon (1955), Edwards (1962), and the research paradigms that followed from the Behavioral Theory of the Firm. Under this tradition, the effects of real-world characteristics of decisions were investigated, such as time constraints, delays in feedback and cognitive workload, and how people handle such environmental constraints and learning everything. This process.

The thought cannot be thought stable and according to general objectives, the individuals that make up the group responsible for decision making are the matrix of ramification of the objectives, which are rationally subjective and then give coherence to what has to be decided, with personal interests, as a result of the rational limitations offered by the generalization to which it subscribes. Due to this, the learning of the predictive becomes a meta-theoretical challenge about the rationality of the organization; Only from this challenge can the organizational objective be generalized: "Learning, in the sense of reacting to perceived consequences, is the main way in which rationality manifests itself" (Simon, 1978, p.162) cited in (Hart \& Banbury (1994).

In the solution of problems, human thinking is governed by programs that organize a multitude of simple information processes, in ordered and complex sequences that respond and adapt to the environment of the task and to the data extracted from that environment as develop the sequences. The secret of problem solving is that there are no secrets: it is done through complex structures of simple and familiar elements of learning in a decision process (Simon., 1979).

\section{Conclusions}

From a rational point of view, Simon (1979) states that choice is the process by which an alternative behavior for each moment is selected. For this, the possible alternatives must be selected, determine the consequences of each alternative and compare them. Being able to determine the consequences of the decisions taken is complex, since we must know the actions of other individuals or firms. However, from a logic of the limits of rationality in individual behavior it is not possible to reach a high degree of rationality (Simon 1947). 
Choices made by an individual usually take place in an environment where premises are given, which are accepted as the basis of choice; and the behavior only fits within the limits set by these given environments. One of the functions of the organization is to establish its members in such a psychological environment that it helps to adapt their choices to the objectives of the firm, providing the necessary information to make their decisions.

Bounded rationality occurs when companies lack perfect information, that is, they do not have context information about the results of their actions, for example; they have bounded resources, and are restricted to the ability to process information. Under these conditions, firms are forced to make decisions, based on the data available for this, their resources and capacities to process information (Simon., 1979). This implies that firms can make decisions that are not completely optimal because they have to adjust to the conditions in which they operate.

Decisions involve a commitment of large amounts of resources of the organization for the fulfillment of the objectives and purposes of the organization through the appropriate means. These means can be translated into models that help reduce the limits of rationality in companies (Grosvold., Stephan, \& Hoejmose, 2013).

\section{Recommendations}

Addressing the bounded rationality and complexity of the problems that organizations have to deal with, implies that the personnel of the organizations adopt a number of reductionist strategies, that is, that allows them to simplify their representation of the situation that presents a problem, trying to include the outstanding information, before trying to model the objective reality. For example, to contribute to a better understanding of the decision-making processes, recent research has reduced the control tasks to its fundamental elements: a stock, an inflow and an outflow, and called for judgments about the relationships between these elements over time (Gonzalez \& Pegah, 2017).

Recent efforts present cognitive explanations of failure in decision making, suggesting the importance of human capacity to observe the similarities between experienced patterns of behavior.

Although research on complex and dynamic tasks will continue to inform the limits of human behavior. By studying simple tasks, we can focus on the study of human decisions that depend on the relationships between choices and their effects over time, and thus in the decision process, when repeated decisions are made, it can be observed and obtained feedback on the results.

\section{References}

Aguirre, R. J. (2007). Aproximación a la teoría de la decisión. Lúmina, 108-122.

Aumann, R. J. (1997). Rationality and Bounded Rationality. Games and economic Behavior, 2-14.

Barnard, C. (1938). The functions of the executive. Cambridge.: MA: Harvard University press.

Barnard, C. I. (1938). The Functions of the Executive (thirtieth Anniversary ed). Cambridge: Harvard university press.

Busemeyer, J. R., \& Bruza, P. (2012). Quantum models of cognition and decision. New York: Cambride University Press.

Conslick, J. (1996). Why bounded rationality? Journal of Economic Literature, American Economic Association., 669-700.

Cyert, R. M., \& March, J. G. (1963). A behavioral theory of the firm. Upper Saddle River, NJ, US: Prentice Hall/Pearson Education. 
Eduards, W. (1954). The theory of decision making. psycological boletin.

Eduards, W. (1962). Utility, subjective probability, their interaction,. PSYCHOLOGICAL BULLETIN Vol. 51 No. 4, 380-411.

Egan, A. (2007). Some Counterexamples to Causal Decision Theory. Philosophical Review (116), 93-114.

Elster, J. (1990). The limits of rationality. Chicago: University of chicago press.

Gonzalez, C. (2012). Training decisions from experience with decisionmaking games. Apative technologies for training and education 167-178. Pittsburg: Cambridge University Press.

Gonzalez, C., \& Pegah, F. (2017). Dynamic Decision Making: Learning Processes and new reseach direction. At the front of HF/E (invited min-review), 1-9.

Grosvold., Stephan, J., \& Hoejmose, U. (2013). Reputational risks and sustainable supply chain: decision making under bounded rationality. emerald insight, 695-719.

Hart, S., \& Banbury, C. (1994). How strategy making procesess can make a difference. Strategic Managements Journal, 251-269.

Luhmann, N. (1997). Organización y decisión, acción y entendimiento comunicativo. Anthropos.

Mahoney Joseph, T. (2012). Economic Fundation Strategy. Urbana-Champaign: University of Illinois.

March, J., \& Simon, H. (1958). Organizations. Oxford, England.: Wiley.

Mintzberg, H., \& Westley, F. (2001). Decision making: ti's not what you think. MIT Sloan Management, 89-93.

Mitchell, T. M. (2008). Predicting human brain activity associated with the meanings of nouns. Nature Reviews Neuroscience 9, 1191-1195.

Paul, S., \& Fischhoff, B. (1977). Behavioral Decision theory. New England: annu. Rev. Psychol. school.

Raport, A. (1975). Research Paradigms for Studying Dynamic Decision Behavior. In: Utility, Probability, and Human Decision Making. Rome: Wendt D., Vlek C.

Simon. (1947). Administrativve Behavior: A study of Decisión Making Processes in Administrative Organization. New York: New York: Free Press.

Simon, H. (1955). A Behavioral Model of Rational Choice. Quarterly Journal Of Economics, 189210.

Simon, H. A. (1957). Models of Man; Social and Rational. Ney York.: Wiley.

Simon, H. A. (1978). Rationality as Process and as an a Product of Thought. The American Economic Review, 1-16.

Simon, H. A. (1982). Models Of Bounded Rationality. Economic Analysis and Public Policy. Volume 2: Behavioural Economics and Business Organization, 478-505.

Simon, H. A. (1997). Models of Bounded Rationality. Cambridge, Massachusetts. England.: The MIT press.

Simon, H. A. (2000). Bounded rationality in social science: Today and tomorrow. Mind \& Society, Vol. 1, Issue 1., 25-39.

Simon. (1979). Rational Decision Making in Business Organizations. American economic review, 498-513.

Vargas-Hernández, J. G., Guerra-García, E., Bojórquez-Gutiérrez, A., \& Bojórquez-Gutiérrez, F. (2014). Gestión Estratégica de Organizaciones. Autónoma de Buenos Aires: Elaleph.

Williamson, O. E. (1979). Transaction-Cost Economics: The Governance of Contractual Relations,. The Journal of Law and Economics, 233-261. 